\title{
Reversible but risky: Pulmonary hypertension in advanced heart failure is the Achilles' heel of cardiac transplantation
}

\author{
Christian A. Bermudez, MD, ${ }^{a}$ and J. Eduardo Rame, MD, MPhil ${ }^{\mathrm{b}}$ \\ From the Divisions of ${ }^{\mathrm{a} C}$ Cardiovascular Surgery and ${ }^{\mathrm{b}}$ Cardiovascular Medicine, University of Pennsylvania Health \\ System, Philadelphia, Pa. \\ Disclosures: Authors have nothing to disclose with regard to commercial support. \\ Received for publication July 27, 2015; accepted for publication July 28, 2015; available ahead of print Sept 10, \\ 2015. \\ Address for reprints: Christian A. Bermudez, MD, Division of Cardiovascular Surgery, Hospital of the University \\ of Pennsylvania, 3400 Spruce St, 6th Fl Silverstein, Philadelphia, PA 19104 (E-mail: christian.bermudez@ \\ uphs.upenn.edu). \\ J Thorac Cardiovasc Surg 2015;150:1362-3 \\ $0022-5223 / \$ 36.00$ \\ Copyright (c) 2015 by The American Association for Thoracic Surgery \\ http://dx.doi.org/10.1016/j.jtcvs.2015.07.098
}

In this issue of the Journal, Tsukashita and colleagues ${ }^{1}$ report the effect of continuous-flow left ventricular assist device (LVAD) support on pulmonary vascular resistance (PVR) in 227 candidates for orthotopic heart transplant (OHT) and compared posttransplantation outcomes in 150 of these patients, including 30 with severe pulmonary hypertension (PH) (ie, PVR >5 WU pre-LVAD). Despite a significant decrease in the mean pulmonary artery pressure with LVAD support (to a level commensurate with LVAD recipients classified as having low PVR), the presence of severe $\mathrm{PH}$ was associated with increased in-hospital mortality $(20 \%$ vs $5.8 \%)$ after OHT with a strong predictive value. The authors conclude that PVR was reduced after LVAD implantation even in patients with severe PH refractory to pulmonary vasodilators, despite the improvement in PVR, patients with severe $\mathrm{PH}$ had higher early mortality after OHT, and the long-term survival did not differ between OHT recipients with high and low PVR (Figure 1).

$\mathrm{PH}$ is present in $40 \%$ to $75 \%$ of patients with advanced heart failure. ${ }^{2}$ LVAD implantation decreases PVR by unloading the left ventricle, reducing pulmonary venous pressure, and augmenting cardiac output. This reduction in PVR seems to be durable and maintained after OHT. $^{3-11}$ The reduction in PVR imparted by LVAD support is highly relevant in patients supported with an LVAD as a bridge to OHT. It may allow OHT candidacy of patients previously deemed not transplant-eligible, and no improvement or a marginal improvement in PVR after LVAD implantation may be associated with prohibitive surgical risk for OHT. Initially, some series demonstrated comparable early and late outcomes in patients with $\mathrm{PH}$ supported with an LVAD. ${ }^{7,10}$ However, other reports have noted higher perioperative mortality and more right ventricular failure in patients with severe $\mathrm{PH}$ who received an $\mathrm{OHT}^{3,6,8}$ It is important to note that the severity of $\mathrm{PH}$, criteria for LVAD implantation, and definition of responsiveness to treatment have been

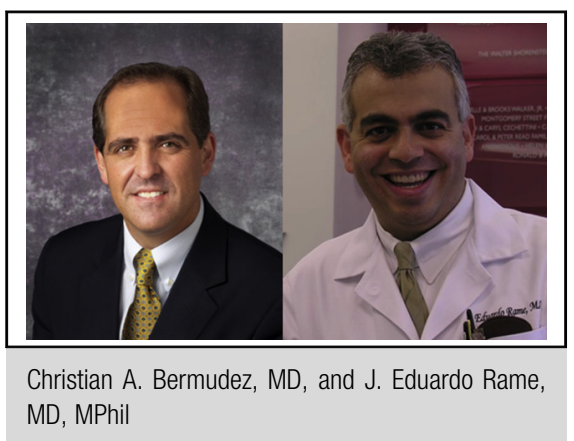

Central Message

Tsukashita and colleagues examined the influence of LVAD use in heart transplant candidates with pulmonary hypertension, but important questions remain unanswered.

See Article page 1352 .

heterogeneous across previously published studies. The time needed for the pulmonary pressure to decrease to allow consideration for OHT has also been variable among published series-from days to weeks after LVAD implantation-and 1 series suggested no additional benefit after 6 months of LVAD support. ${ }^{3,7,12}$

The study by Tsukashita and colleagues ${ }^{1}$ is the largest single-center experience to date on the effects of preexisting $\mathrm{PH}$ on OHT outcomes in patients bridged with continuousflow LVADs, and provides relevant information on the use of continuous-flow LVADs at a highly specialized center. With an optimistic interpretation, the authors confirm that $66 \%$ of patients with severe $\mathrm{PH}$, who in the absence of LVAD would have not been OHT candidates, underwent transplant. The vast majority of these patients presented with a significant improvement in $\mathrm{PH}$ as early as 37 days after LVAD placement, although only $40 \%$ received pulmonary vasodilator treatment during LVAD support. At the same time, the higher perioperative mortality of $20 \%$, mostly due to primary graft dysfunction, reminds us that this patient population should still be considered high risk.

Not infrequently, patients with severe PH before LVAD implantation will present with severe primary graft dysfunction after OHT, commonly triggered by right ventricular dysfunction, ${ }^{3,8}$ consistent with the findings of the study by Tsukashita and colleagues. ${ }^{1}$ One possible reason is that although PVR decreases with LVAD 


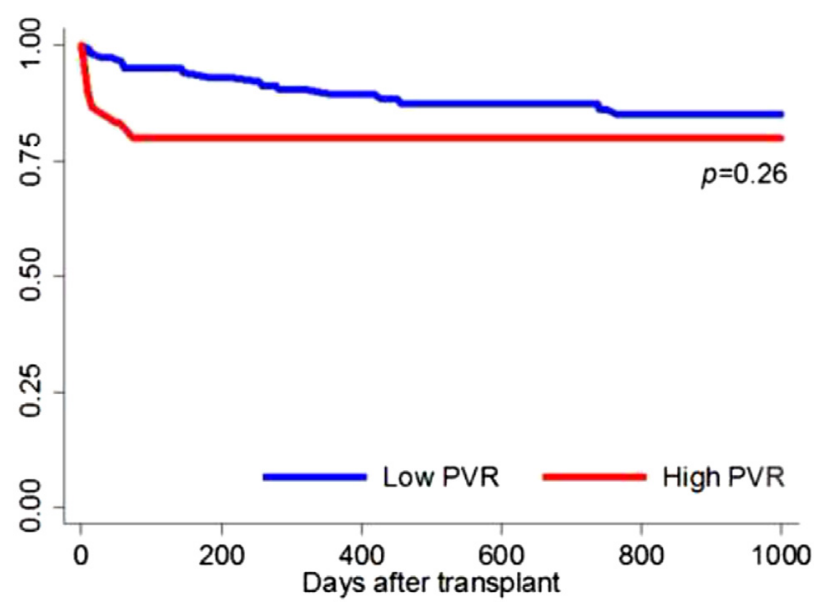

FIGURE 1. Kaplan-Meier survival curve during left ventricular assist device support. ${ }^{1} P V R$, Pulmonary vascular resistance.

support, reversal of pulmonary vascular remodeling is heterogeneous or incomplete, and the pulmonary arteriopathy that remains may provide a substrate for a pulmonary hypertensive crisis triggered by perioperative insults, including insulin resistance from cardiopulmonary bypass and depletion of nitric oxide associated with the transfusion of stored packed red cells.

Unfortunately, there are scarce data on the efficacy of pulmonary vasodilator therapy in patients with severe $\mathrm{PH}$ on long-term LVAD support. Tedford and colleagues ${ }^{13}$ demonstrated an encouraging drop in PVR (from 5.8 to $2.96 \mathrm{WU}$ ) in patients who received sildenafil, a PDE-5 inhibitor. LaRue and colleagues ${ }^{14}$ identified a drop in PVR (from 3.9 to $1.5 \mathrm{WU}$ ) in patients who were treated with an endothelin-receptor antagonist (ERA). ${ }^{14}$ We hope to learn more about the tolerability and efficacy of ERAs during an upcoming randomized clinical trial of ERA treatment initiated within 1 month of LVAD implantation in patients with increased PVR (the SOPRANO [macitentan in pulmonary hypertenSiOn Post left ventRiculAr assist device implaNtatiOn] study).

The elegant study by Tsukashita and colleagues ${ }^{1}$ helps us understand the effects of continuous-flow LVAD implantation in secondary $\mathrm{PH}$ and outcomes of OHT, but important questions remain unanswered, including the potential role of adjunctive pulmonary vasodilator therapy and the time of support needed to minimize the perioperative risks of OHT. Given the higher risk of perioperative mortality in patients with severe $\mathrm{PH}$ before continuous-flow LVAD support in this study ${ }^{1}$ and consistent with our clinical experience, LVAD therapy is not a universal solution. In selected cases, maintaining LVAD support, even in the presence of right-sided heart failure, may be superior strategy to forging ahead with a high-risk heart transplant.

\section{References}

1. Tsukashita M, Takayama M, Takeda K, Han J, Colombo PC, Yuzefpolskaya M et al. Effect of pulmonary vascular resistance prior to left ventricular assist device implantation on short- and long-term post-transplant survival. J Thorac Cardiovasc Surg. 2015;150:1352-61.e2.

2. Khush KK, Tasissa G, Butler J, McGlothlin D, De Marco T, ESCAPE Investigators. Effect of pulmonary hypertension on clinical outcomes in advanced heart failure: analysis of the Evaluation Study of Congestive Heart Failure and Pulmonary Artery Catheterization Effectiveness (ESCAPE) database. Am Heart J. 2009;157:1026-34.

3. Alba AC, Rao V, Ross HJ, Jensen AS, Sander K, Gustafsson F, et al. Impact of fixed pulmonary hypertension on post-heart transplant outcomes in bridge-to-transplant patients. J Heart Lung Transplant. 2010;29:1253-8.

4. Atluri P, Fairman AS, MacArthur JW, Goldstone AB, Cohen JE, Howard JL, et al. Continuous flow left ventricular assist device implant significantly improves pulmonary hypertension, right ventricular contractility, and tricuspid valve competence. J Cardiac Surg. 2013;28:770-5.

5. Etz CD, Welp HA, Tjan TD, Hoffmeier A, Weigang E, Scheld HH, et al. Medically refractory pulmonary hypertension: treatment with nonpulsatile left ventricular assist devices. Ann Thoracic Surg. 2007;83:1697-705.

6. John R, Liao K, Kamdar F, Eckman P, Boyle A, Colvin-Adams M. Effects on pre- and posttransplant pulmonary hemodynamics in patients with continuous-flow left ventricular assist devices. J Thorac Cardiovasc Surg. 2010;140:447-52.

7. Nair PK, Kormos RL, Teuteberg JJ, Mathier MA, Bermudez CA, Toyoda Y, et al. Pulsatile left ventricular assist device support as a bridge to decision in patients with end-stage heart failure complicated by pulmonary hypertension. J Heart Lung Transplant. 2010;29:201-8.

8. Torre-Amione G, Southard RE, Loebe MM, Youker KA, Bruckner B, Estep JD, et al. Reversal of secondary pulmonary hypertension by axial and pulsatile mechanical circulatory support. J Heart Lung Transplant. 2010;29:195-200.

9. Zimpfer D, Zrunek P, Roethy W, Czerny M, Schima H, Huber L, et al. Left ventricular assist devices decrease fixed pulmonary hypertension in cardiac transplant candidates. J Thorac Cardiovasc Surg. 2007;133:689-95.

10. Zimpfer D, Zrunek P, Sandner S, Schima H, Grimm M, Zuckermann A, et al. Post-transplant survival after lowering fixed pulmonary hypertension using left ventricular assist devices. Eur Journal Cardiothorac Surg. 2007;31:698-702.

11. Drews T, Jurmann M, Michael D, Miralem P, Weng Y, Hetzer R. Differences in pulsatile and non-pulsatile mechanical circulatory support in long-term use. J Heart Lung Transplant. 2008;27:1096-101.

12. Mikus E, Stepanenko A, Krabatsch T, Loforte A, Dandel M, Lehmkuhl HB, et al Reversibility of fixed pulmonary hypertension in left ventricular assist device support recipients. Eur J Cardio Thorac Surg. 2011;40:971-7.

13. Tedford RJ, Hemnes AR, Russell SD, Wittstein IS, Mahmud M, Zaiman AL, et al. PDE5A inhibitor treatment of persistent pulmonary hypertension after mechanical circulatory support. Circ Heart Fail. 2008;1:213-9.

14. LaRue SJ, Garcia-Cortes R, Nassif ME, Vader JM, Ray S, Ravichandran A, et al Treatment of secondary pulmonary hypertension with bosentan after left ventricular assist device implantation. Cardiovasc Ther. 2015;33:50-5. 